\title{
Teacher Education's Mechanism Innovation Research Based on the Industry Institute Mode
}

\author{
Fu Jinlan \\ Zaozhuang University, Zaozhuang, Shandong Province 277160, China \\ email: ghj7507@126.com
}

Keywords: industry institute mode, joint operation of schools, linking mechanism

\begin{abstract}
In order to train high level and practical talents, the mode of compound talents training has become the target of colleges and universities. Through the cooperation of school and enterprise, profession connecting with industry is a way to achieve cooperative development. This article focuses on practice-oriented talents training mechanism to cultivate para-professionals of enterprise. Taking teacher profession for example, we try to find a suitable normal operational mechanism of local colleges, to cultivate students' better social adaptability and competitiveness to achieve the core goal of application-oriented talents training.
\end{abstract}

\section{Introduction}

The documents of "The National Plan for Medium and Long-term Education Reform and Development (2010-2020)" and "Shandong Province Medium and Long-term Education Reform and Development Plan (2011-2020)" put forward that reform and innovation should be regarded as a powerful driving force for the development of the education. Innovating operation of school system and management system should jointly run with forces of social and enterprise and introduce high quality educational resources to raise the level of international cooperation. Innovation in application-oriented students cultivating model can meet more diverse educational needs. From the perspective of overall personnel training system, cultivating application-oriented students that the society needs, building industry-oriented talents training mode become one of the most important tasks of the university construction and development.

University and enterprises carrying out joint training of personnel have become a trend. In the 1980s, the United States has already carried out reforms of teacher education programs, appearing a kind of teacher education model mixing pre-service training with in-service training reform, known as the "professional development schools". It promotes the level of students' practical skill training, further more students can have opportunities to learn practical knowledge and field operations, hence the talent training modes jointly with the industries can make up for the defects of teacher education in universities .

Since the United States implemented cooperation by production, study and research, the industry institute personnel training mode began to set off a worldwide educational reform. So a new mode of talents cultivating came into being, combining enterprises with higher school which aims to enhance students' professional quality. In side of classroom teaching mode, the teaching modes can cultivate students' innovative ability to meet teaching objectives pluralism, and individual needs in the process of learning constantly. Focusing on teachers' qualifications became an important 
objective of teacher education reform in Japan. Japan adopted teachers' open training system, and the opening practice, so field training mode became an obvious feature of teacher's training mode reform.

Inland from 2013, there are ten institutes being set up. These universities and industries established double subjects' colleges in terms of school-enterprise cooperation which has proved extremely valuable in talent training mode. In March 2015, on Institute Symposium, National Open University President Yang Zhijian pointed out that enterprise school building was the implementation of spirit of "the University in Society" and achieved the requires of "feature developments, misplaced developments".

Now teacher education in China is in transition, which mainly reflects transmission from the traditional three-tier system to two-tier system. In short term schools could not complete transformation of teachers' groups and could not meet industry's personnel needs. Further more colleges are not closely affiliated with businesses, and the cooperation between schools and enterprises is often limited to the text of the agreement, which is just a form of cooperation, that is, joint training just stays on the surface. In addition, the problem of theory and practice is an unanswered question. One important reason is that people often take into account the complex challenges from a single dimension, examine the nature of the problem from single dimension and the corresponding strategy is single-dimensioned. Further more attributing teacher education problems to a particular point of theory or practice is not appropriate. Therefore, we need to transform the united teachers' training mode, change the concept of education, emphasize on the character of education teacher as well as the character of practice and application. And we should focus on exploring a fusing model to make the business model adapt to social needs.

\section{Main text}

\subsection{University and industry cooperating in joint training}

\subsubsection{Personnel training building on firm ground}

Models of teacher education from closed to open have become a world trend. Joint cooperation between university and industry training, aims at resolving the discrepancy between higher education and social needs, and changes the phenomena of "floating magnetic" of teacher education to a state of integration. This training mode enables teacher profession not only out of its closed circle, but also out of the university, and penetrate into teachers' main future activity fields, which makes the suspended teacher profession fall to where it should be. The combination of knowledge-oriented school education and practice-oriented entrepreneurship can realize the "seamless link" of personnel training and the employer's department. Therefore, the combination of schools and enterprises could cooperate organically, share resources with each other, promote both the development of colleges and students' growth, as well as promote the development of local industries and enterprises, which eventually will achieve a win-win situation.

\subsubsection{Co-cultivate different levels of talents}

Facing with new demands for talents in various sectors of society, many local colleges have to objectively and subjectively cooperate with industries, especially from aspects of personnel training, scientific research, social services, product design and innovation etc. Therefore, the industry background should be the logical starting point for teachers' professional training system, which requires colleges to expand the depth and lateral in conjunction with industry.

With the deepening of curriculum reform of basic education, the promulgation and implementation of curricula in basic education courses in the areas of content and structure, curriculum development and evaluation have had great changes. The standards of basic education 
demands continue to improve, which is not only opportunity but also challenge for students. In the process of meeting the challenges, the personnel training modes are in urgent need of reform pointing to the teaching practice of teacher education and professional development. The newly-built undergraduate colleges of education, through cooperation with industry manufacturers can form a community in expanding the scope of school services and student employments. The enterprise course system should be obvious, professional, or specific. Around the training objectives and the mode of "order" training, colleges and enterprise jointly develop professional courses, and ultimately realize the training objectives of social development, as well as industry demands.

\subsection{Colleges with enterprises creating a new educational model}

According to the actual needs of society and the employers, college and industry professionals jointly make training programs and courses. According to the designing ideas of "country's requests + school positioning + enterprise requests + professional features", college and industry highlight the characteristics and advantages of cooperative education and service objects. Throughout the training process, colleges work closely with local industries and enterprises, implement cooperative education, collaboratively develop training programs, construct teacher groups, and participate in customized training, so as to promote student employments.

Colleges revise personnel training programs together with industry sectors to jointly develop curriculum modules. Undergraduate cultivating can carry out " $3+1$ "system, that is, students" learning is divided into learning in and after school. The contents include school courses in cooperation with the industry or educational enterprise work. That is, in setting the cooperation cycle, students participate in a whole cooperative training process. In the earlier three years students complete professional education curricula in school education. Last year enterprise module curricula can be implemented, combining professional elementary education with vocational skills training, which can help each student find work position or role. The module curricula are designed for a specific job in order to develop job-specific professional competence. It is the continuation of the professional elective course, helping students integrate professional knowledge in some certain areas of theory and practice. During learning industry module courses, practical work can be managed by local industry, and supervised by colleges. The evaluation of student performance is mainly determined by local enterprise department. In conclusion, the first stage is the application of our existing personnel training model, in which the existing practice is unchanged, the second stage is the fourth year of enterprise training model. And the institute of industry is affiliated to college of teachers education.

In the well-designed professional education's required courses and elective courses, the mode of college and enterpriser cooperation can break the polarization, linear training mode. About the arrangement on teachers, industry expert counseling system is introduced. Students learn from industry experts about how to create or design lesson plans. Around the realization of application-oriented talents cultivating objective, using extracurricular system as an extension of education theory, the enterprise training mode can meet the occupational criteria requirements, reconstruct the course's logical relationship, reform teaching contents and methods, and promote the integration and optimization of teacher's professional curricula.

In industry module phase, according to industry sector, with the principle of voluntary, students can independently apply for learning modules. The industry needs-oriented schools and agencies design sector demand modules, detailing modules of curriculum contents and teaching methods. At this stage, we mainly draw from library-related courses to form some personalized curricula, and implement the designed modules in practice. It is only by this way can we show the personalized orientation between industry needs and the students from varied professional backgrounds. Next we take the training of pre-primary and primary education as examples to illustrate. 
In personnel training of preschool education major, the early childhood education management mode, there can be director module for entrepreneurial students; science education module for teachers; nursing module, which can form a plurality of individual modules. Module such as director, is in accordance with the principal of posts provided for the actual work of course, which is work-oriented, and can open module courses, such as the kindergarten building, staff recruitment and staff development, salary system construction, communication courses, etc.

In primary school of professional education training, there may be scientific education teacher module, mental health education teacher module, class module, and personalized curriculum module such as team counselor module. Class module, according to head teacher posts provides for the actual work of course, which is work-oriented, and can open module curricula of class construction, class leader appointing, class formation and development, rewarding or punishment system, etc. The course of class module, which can't be learned in school, and there is no practice field, so there must be by means of cooperation with industry professionals.

\section{Conclusions}

Firstly, independent operating mechanism is necessary. Independent mechanism is embodied in accordance with enterprise model in creating situations for training, which copies the formation of "trades people", so as to form an independent personnel training and management team.

Secondly, there should be a linkage mechanism. Linkage mechanism is embodied in the industry-oriented teachers' professional training system involving the government, schools, local educational administrations. This mechanism requires secondary institute with education sector in equal status to participate in the cultivating of teachers, and make the fragmented, decentralized training institutions and employers together form a cohesive force, and provide the complete field for application-oriented talents to grow. Enterprises can take advantage of existing educational resources for teachers in colleges and organizations to achieve win-win, such as task oriented cooperation, training oriented cooperation, employment oriented cooperation, and the pupils' creative training oriented cooperation.

Thirdly, the incentive mechanism. Incentive mechanism should include the institutional arrangements and policy orientation of the local colleges. Local colleges can recognize and encourage elementary school and teachers' intellectual and labor achievements in terms of policy, so as to support and guide education reform as effective ways.

Finally, the quality information feedback mechanism. Colleges should establish enterprise quality information feedback system, choose excellent object from the industries as the basis for indicator development, taking into account knowledge and capability index indicators, and absorb industry experts to evaluate the quality of training, and talent cultivating process, etc.

\section{Acknowledgements}

The article is a part of results of the Project of Undergraduate Teaching Reform of Shandong Province Universities in 2015(NO:2015M215)

\section{References}

[1] Li Jin. An Introduction to Teacher Education[M]. Beijing: Peking University Press, 2009.86

[2] Zhao Minna. A Case Study of Three Typical Classroom Teaching Mode of Colleges in United States [J]. Comparative Education Research, 2004 (4)

[3] Liu Huaqiang. "Double-three” Model Cultivation Practice and Consideration of High Skilled Talents [J]. Journal of the Chinese Academy of Social Sciences, 2013 (1) 
[4] Yang Shanjiang. Fusion of Producing and Education: the Only Route of the Development of Modern Vocational Education in Deep Industry Transition[J]. Journal of Education and Profession, 2014(33)

[5] Wang Hui. Collaboration between Colleges and Enterprises Boosting Integration Production and Education: the Rise of American Community College University-enterprise Cooperation Programs[J]. Journal of Higher Education Research, 2015(3)

[6] Ge Chun-Feng. Construction of Professional Groups of Newly-built Applied Undergraduate Universities and Colleges[J]. Journal of Higher Vocational Education, 2013 (2) 